\title{
t JURNAL \\ Severe Constricted Head - An Extreme Form Of Crouzon Syndrome Posing Challenging Fronto-Orbital Advancement : Case Reports
}

\author{
Ciptomurti J. Lupitasari a, Lobredia Zarasade a*, Magda R. Hutagalung a \\ aDepartment of Plastic Reconstructive and Aesthetic Surgery, Faculty of Medicine Universitas Airlangga \\ ${ }^{*}$ Corresponding author: Lobredia Zarasade - Department of Plastic Reconstructive and Aesthetic Surgery, \\ Faculty of Medicine Universitas Airlangga. Email address : lobredia@gmail.com
}

ARTICLE INFO

Keywords:

Crouzon syndrome

Constricted head

Arduous surgical

technique

\begin{abstract}
Background : Constricted head or cloverleaf deformity in Crouzon syndrome is a severe form of the syndrome involving trilobed coronal and lambdoid synostosis. Crouzon syndrome with acanthosis nigricans is distinct from the classic Crouzon syndrome, characterized by thick and dark skin in body folds. The major problems resulting from constricted head are related to craniostenosis, orbitostenosis developing from abnormalities of the skull base associated with progressive rise in intracranial and intraorbital pressures which could progress to hydrocephalus and cerebellar herniation.

Case: Two cases with severe Crouzon syndrome were reported. The first was a five month old girl associated with acanthosis nigricans and the other was a sixteen month old boy, both whose phenotypic expressions were at the extreme severe end of the disease spectrum. On examination there was serious corneal exposure, visual loss, severely narrow head, midface hypoplasia, and beaked nose. CT scan showed typical cloverleaf skull, expanded middle cranial fossa, foreshortened anterior and posterior fossae and honeycomb appearance in the occiput involving pansutural synostosis and extensive copper beaten deformity from the high intracranial pressure . Both were complicated with hydrocephalus requiring ventriculoperitoneal shunt. This required an arduous effort in releasing the brain from the multiply punctured calvaria, avoiding excessive dural tear and bleeding and ultimately preserving the brain. Excessive bleeding was also caused by the raised ICP. Both patients are planned to undergo occipital expansion three months later. Conclusion: Severely constricted head in Crouzon syndrome is an extreme manifestation and late stage of the syndrome which not only will result in irreversible complication but will require meticulous surgical technique.
\end{abstract}

$\mathrm{M}$ odern era of craniostenosis surgical treatment began in 1970, when plastic surgeons and neurosurgeons joined forces to form craniofacial teams and described new techniques to solve the functional and the structural problems at the same time. The techniques developed at the Hopital des Enfants Malades in Paris were published in detail in 1982, and although some minor changes have been introduced the basic techiques remain unchanged after treatment of over 1.600 patients3.

Crouzon Syndrome is among the rare syndromic craniosynostosis inherited by autosomal dominant transmission, affecting cranial development in consequence of formation from two or more suture premature fusion called craniofacial dysostosis. This is characterized by craniosynostosis, exophthalmos, and midface 
hypoplasia. The birth prevalence of Crouzon syndrome is estimated to be $15-16$ per one million births3.

The majority of patients with Crouzon syndrome have mutations in the extracellular immunoglobulin III domain of the fibroblast growth-factor receptor 2 (FGFR2) gene.

Crouzon syndrome with acanthosis nigricans is rare; this condition occurs in about 1 person per million. For unknown reasons, it affects females more than twice as often as males. The genetic change involved in this disorder causes the FGFR3 protein to be overly active, which disrupts the normal growth of skull bones and affects skin pigmentation10. The main point in Crouzonsyndrome is that the synostosis is frequently progressive. Usually, the sutural fusions do not exist at birth. The coronal and sagittal fusions appear at about one year of age, the lambdoid later in life5.

The craniofacial deformity depends on which sutures are affected. Constricted head deformity in Crouzon syndrome is a severe form of the syndrome which may be a consequence of multiple sutural fusion, due to a constriction ring developing in the lambdoid-squamosal zone, causing bulging in the frontal and temporal bones and a trilobar head shape(8).

This constricted head has other names such as cloverleaf skull (CLS), kleeblatshadel and triphylIocephaly9. The main features are cloverleaf deformity characterized by facial hypoplasia involving the orbits causing usually severe exophthalmos, and the nose and upper maxilla and occasionally severe hydrocephalus and poor prognosis due to progressive intracranial hypertension5. The forehead is recessed vertically, with retrusion of the supraorbital rim and root of the nose3. A review article by Cinalli (2005) reported that Chiari I malformation was found in $100 \%$ of cloverleaf skull deformity12. Management of CLS in Crouzon syndrome follows the same established protocols as for other craniosynostosis. Two universally accepted protocols are those from ACFU and Erasmus CF center12.

\section{Case Report}

Presented two cases of severe Crouzon syndrome with constricted head, a five month female baby and a sixteen month male baby who presented to Dr.Soetomo general hospital referred from the general hospitals in their area.

Their chief complaints were progressively abnormal head shapes since birth, difficulty in breathing, inflammation of both eyes, and

Disclosure: The authors herely declare they have no financial interest in the information discussed in this article

progressively rapid visual loss with protruding eyes. They always snored and would wake up suddenly in the night apparently from difficult breathing. Perinatal history was unremarkable. Family history revealed no craniofacial deformity.

\section{Case 1}

A 6 month old female, admitted to hospital with abnormal head shape from birth. She is the second child from her family with normal aterm birth, weight $3300 \mathrm{~g}$, length $49 \mathrm{~cm}$, with normal limbs.

Examination of the head the baby showed severe constricted head clover leaf or trilobular deformity with bulging at the anterior fontanalle like oxycephaly associated with bilateral temporal bulges.

brachicephaly, turricephaly, midface hypoplasia that make a baked nose, with cephalic index 13,3 and head circumference $38 \mathrm{~cm}$

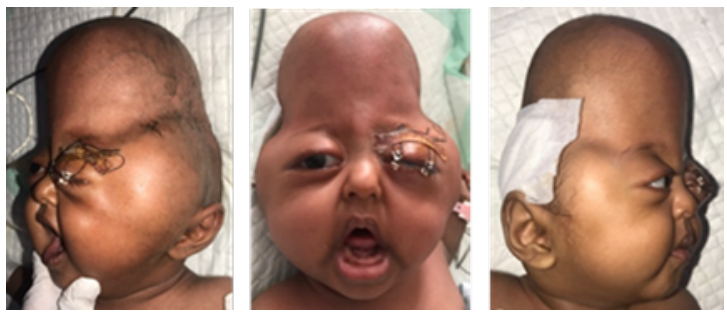

Figure 1. Craniofacialis region from 5 month female patient 
There was bilateral exorbitism with the left eye being very proptotic with constant epiphora since two weeks before she came to Dr.Soetomo general hospital. There was bilateral lagophtalmus, corneal ulcer on the left eye, and exposure keratitis with papil atrophy on the right eye. From ultrasonography examination there was no sign of intraocular infection, and normal vitreoretinal. ENT finding. This patient snored during sleep with nasal congestion without a history apnea. This patient had delayed global developmental problem in both pyschomotor and psychosocial. All extremities were normal in function and morphology. A CT scan of the head showed hydrocephalus non communicans, synostosis of the metopic, bilateral coronal and lambdoid sutures with severe copper beaten appearance

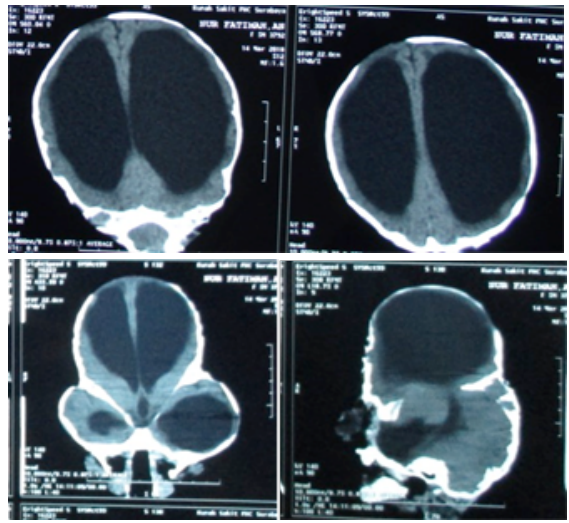

Figure 4. CT-Scan showed cloverleaf deformity and hydrocephalus
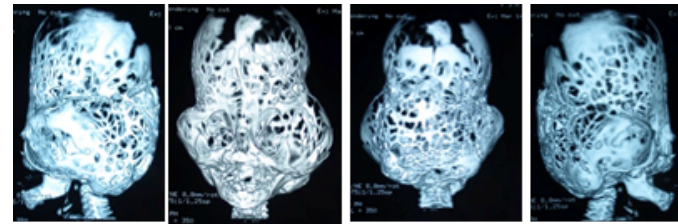

Figure 5. Cranial 3D reconstruction CT-Scan showed copper beaten apearance

This patient had eye infection resulting from severe exorbitism. Surgery had to be postponed until the infection was healed. While awaiting surgery his left eye was protected with a tarsorrhaphy. Soon after arriving at the ER, the neurosurgeon performed a emergency ventriculoperitoneal shunt in which the dissection was difficult due to the entrapped dura in the multiple holes on the thin calvaria causing extensive bleeding. Because long durante and difficult operation cause a lot of $1500 \mathrm{ml}$ bleeding.

It was decided to do a craniotomy/suturectomy, fronto-orbital advancement (FOA) and cranial vault remodelling with the neurosurgical team after splitting the palate to secure the airway after extubation.
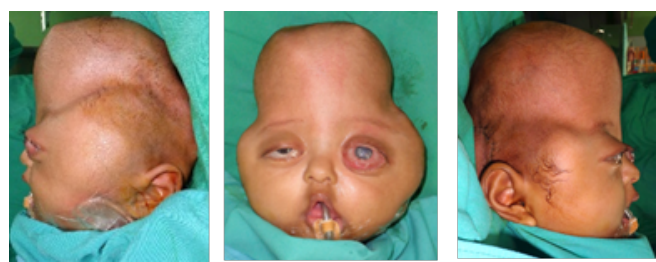

Figure 6. Before fronto-orbital advancement
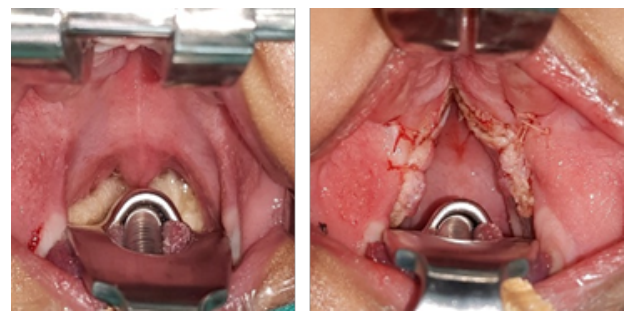

Figure 7. Before and after palatal split, fixing the soft palate to the alveolus with 4.0 silk suture.

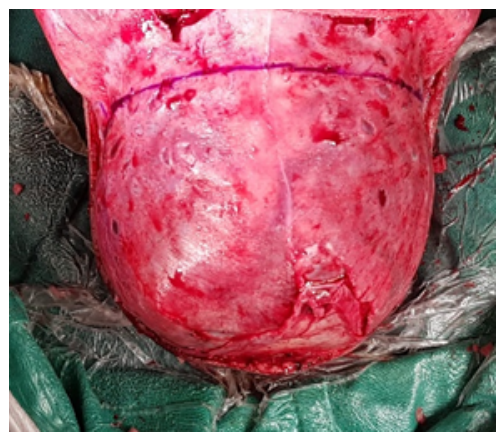

Figure 8. Showed hole in duramater 

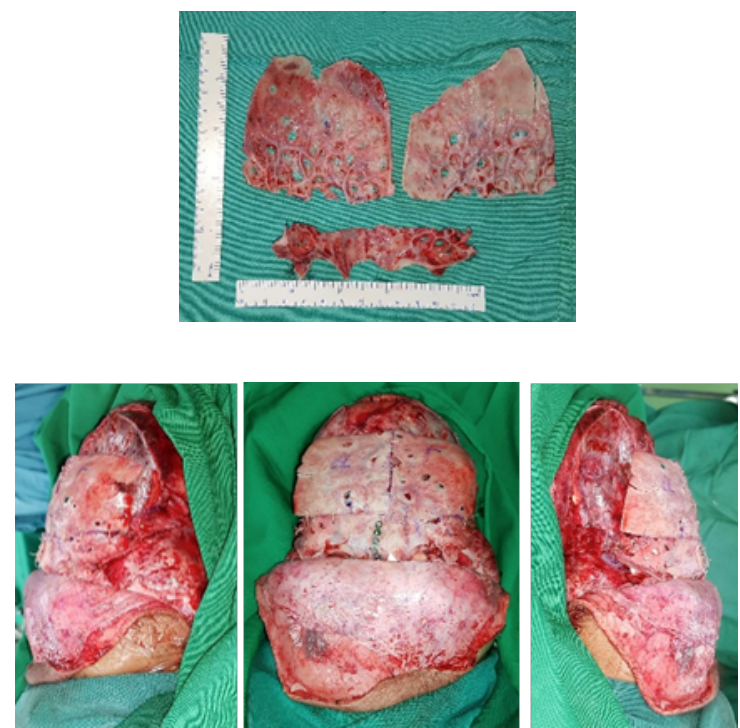

Figure 8. Durante Operation, $1 \mathrm{~cm}$ fronto-orbital advancement
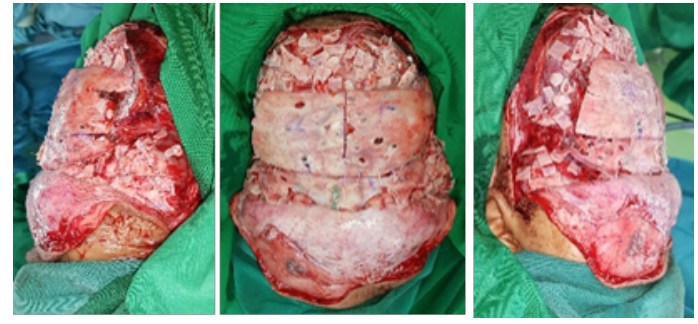

Figure 9. Filling the remaining cranial gaps with fibrin glue and bone chips
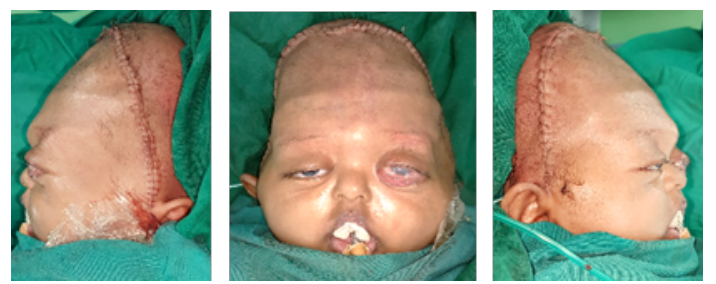

Figure 10. After frontoorbital advancement

\section{Case 2}

A-16 month old male patient was admitted to hospital with abnormal head shape and eyeball protrusion since seven month old before. He is the last child from his family birth atterm with section secaria, weight $3300 \mathrm{~g}$, length $50 \mathrm{~cm}$, with normal limbs. Examination of the head the baby showed severe constricted head clover leaf deformity, brachicephaly, turricephaly, trigonocephaly, with ridging on both coronal, sagital sutures, and both lambdoid sutures with head circumference $47 \mathrm{~cm}$.
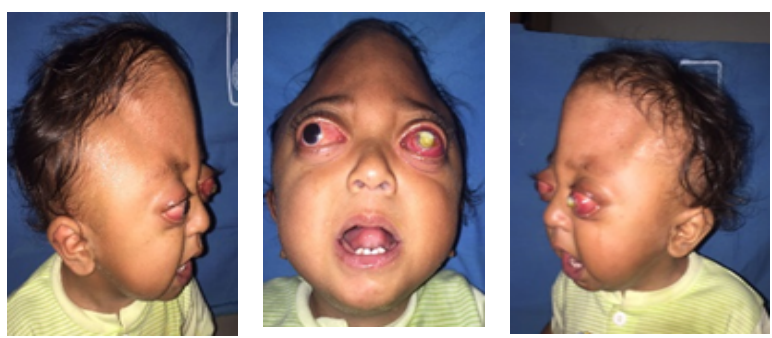

Figure 11. Preoperative appearance

Both eyes were displaced forward whenever baby cried since seven months old. But in thirteen month age, the protrusion became more fixed. There are bilateral lagophtalmus, bilateral proptosis with corneal ulcer on the left eye, and exposure keratitis on the right eye. Intra-oral examination revealed high arched palate, hypoplastic maxilla and chronic adenotonsilitis. Polysomnography revealed mixed moderate central and obstructive sleep apnea. This patient had delayed global developmental problem in both pyschomotor and psychosocial. All extremities were normal in function and morphology.

CT scan showed Kleeblattschadel head deformity with premature closure of sagittal, bilateral coronal, frontal, both lambdoid sutures. Right and left lateral system ventricle III-IV were very dilated indicating a communicating hydrocephalus. The exophthalmos on the right eye protruded 1,16 $\mathrm{cm}$ and the left eye $1,19 \mathrm{~cm}$. 

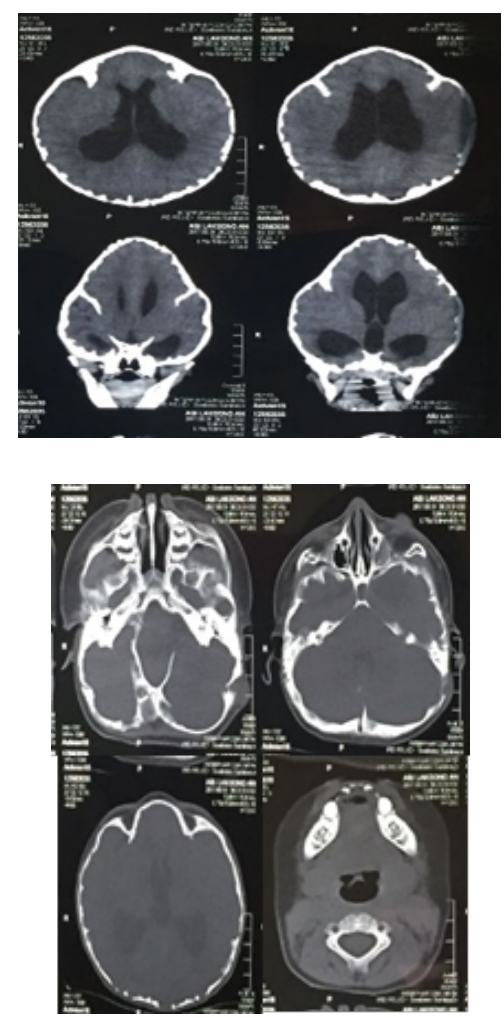

Figure 13. Bone window on computed tomography scan of
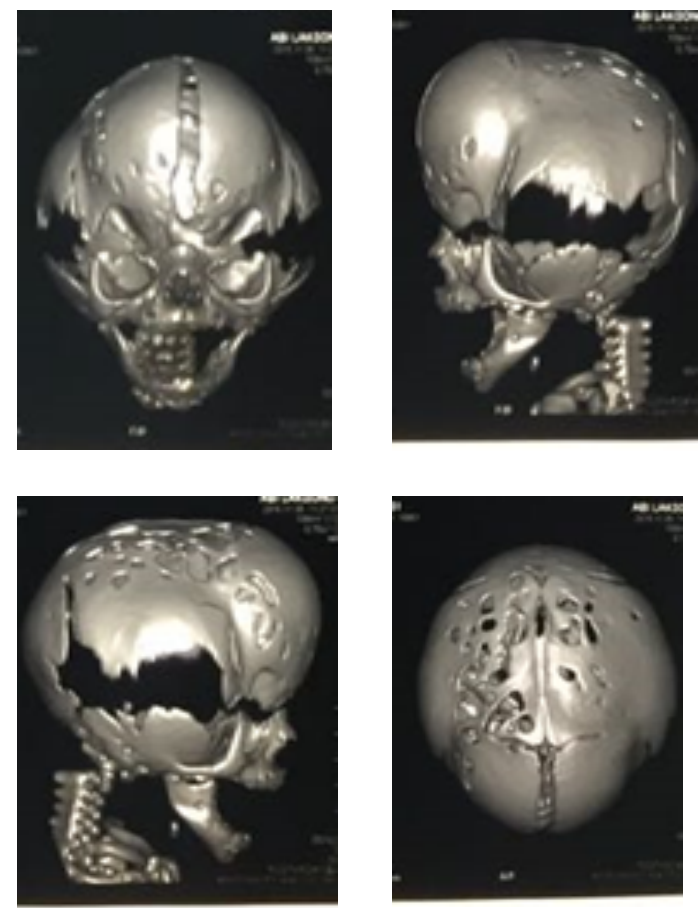

Figure 14. Cranium CT performed; 9 month after fronto-orbital advancement operation
Difficulties from this patient are high intracranial pressure caused by hydrocephalus communicans and make a copper beaten appearance. Difficult airway caused obstructive sleep apnea make a challenge to anesthesiologist. Estimation blood lost of this surgery is $180 \mathrm{ml}$. It was decided to do a split palate to secure the airway after extubation then a craniotomy/suturectomy, fronto-orbital advancement (FOA), cranial vault remodelling and tapping the ventricle with the neurosurgical team after

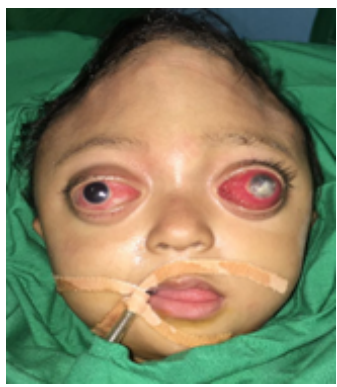

Figure 15. Before advancement

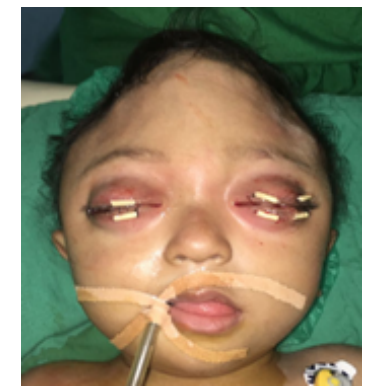

operative fronto-orbital
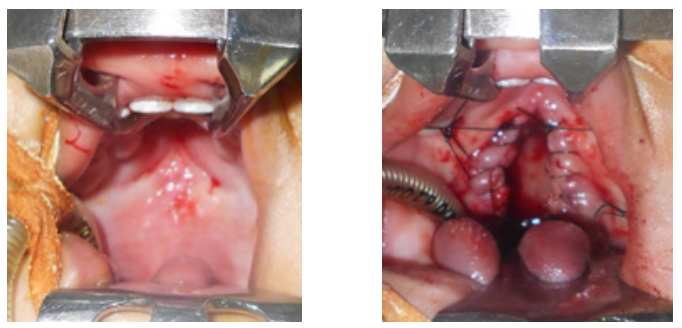

Figure 16. Before and after palatal split, fixing the soft palate to the alveolus with 4.0 silk suture.

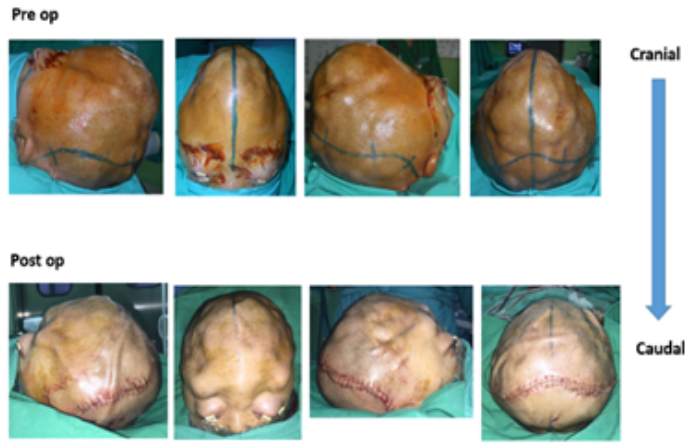


Figure 17. Pre and post fronto-orbital advancement procedure, showed temporo parietal occipital region

\section{Discussion}

Constricted head in the form of CLS or kleeblatshadel can be found in several craniosynostosis syndrome including Crouzon syndrome, Boston type and and Thanatophoric dysplasia type II (11).

Table 1. Showed form of Cloverleaf skull deformity ${ }^{11}$.

\begin{tabular}{|c|c|l|c|}
\hline No. & Condition & \multicolumn{1}{|c|}{$\begin{array}{l}\text { Craniofacial } \\
\text { Phenotype }\end{array}$} & Gene \\
\hline 1. & Boston Type & $\begin{array}{l}\text { Craniosynostosis, } \\
\text { cloverleaf skull, } \\
\text { forehead } \\
\text { retrusion, frontal } \\
\text { boosing. }\end{array}$ & MSX2 \\
\hline 2. & $\begin{array}{c}\text { Thanatop- } \\
\text { horic } \\
\text { dysplasia } \\
\text { type II }\end{array}$ & $\begin{array}{l}\text { Craniosynostosis, } \\
\text { cloverleaf skull, } \\
\text { severe bone } \\
\text { growth } \\
\text { disturbance }\end{array}$ & FGFR3 \\
\hline
\end{tabular}

Both cases were diagnosed with Crouzon syndrome based on clinical findings. Both has CLS which is a severe form of Crouzon syndrome with serious complications including compromised airway and breathing, increased intracranial pressure, visual loss and ulceration. These were neglected cases because of delay in diagnosis and subsequently in treatment.

This condition was supposed to have been managed by standard protocols. In both patients, suturectomy, FOA and cranial vault remodeling were done to correct frontosupraorbital retrusion, to protect the globes and to expand the intracranial volume.

The underlying pathology of a CLS is a constriction ring in the lambdoid-squamosal zone8.
Table 2. Standard protocol from Erasmus CF center12.

\begin{tabular}{|c|c|}
\hline \multicolumn{2}{|c|}{ Australian Craniofacial Unit } \\
\hline Birth -3 months & Total Assessment \\
\hline $3-6$ months & $\begin{array}{l}\text { Planning meeting } \\
\text { Surgery : } \\
\text { - } \quad \text { Fronto-orbital } \\
\quad \text { Advancement } \\
\text { - } \quad \text { Bone Graft } \\
\text { - } \quad \text { Lambdoid } \\
\quad \text { Craniectomy }\end{array}$ \\
\hline 1 year old & $\begin{array}{ll}\text { - } & \text { Total review } \\
\text { - } & \text { Craniofacial clinic }\end{array}$ \\
\hline $1-10$ years old & 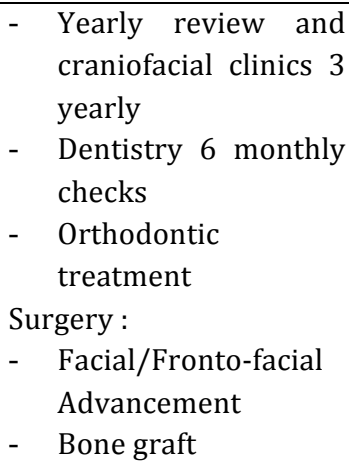 \\
\hline Teenage years & $\begin{array}{ll}\text { - } & \text { Complete Workup } \\
\text { - } & \text { Dentistry } 6 \text { monthly } \\
\text { checks } \\
\text { - } & \text { Orthodontic } \\
& \text { treatment } \\
\text { - } & \text { Orthognathic surgery }\end{array}$ \\
\hline Maturity & Touch-up surgery \\
\hline \multicolumn{2}{|c|}{ Erasmus Medical Center Rotterdam } \\
\hline \multicolumn{2}{|c|}{ Pre operative CT, MRI, Funduscopy, Sleep Study } \\
\hline 6 months & $\begin{array}{ll}\text { - } & \text { Occipital expansion } \\
\text { with springs } \\
\text { - } & \text { Endoscopy of upper } \\
\text { airway } \\
\text { - } \quad \text { If luxating } \\
\text { eyeball/severe OSA : } \\
\text { Early Monobloc }\end{array}$ \\
\hline $\begin{array}{l}8-12 \text { years or }>18 \\
\text { years old }\end{array}$ & $\begin{array}{lll}\text { Monobloc or } & \text { Facial } \\
\text { Bipartition } & & \end{array}$ \\
\hline 18 years old & Le Fort I \pm BSSO \\
\hline
\end{tabular}

Fusion of lambdoid sutures often result in significant posterior cranial fossa volume, narrowing of central nervous system and associated with hydrocephalus which also be caused by venous hypertention 13 . 
The cystic dilatation of the temporal horns is the earliest sign of hydrocephalus and occurs secondary to disturbed growth of the cerebral capsule 9. In both patients, there was hydrocephalus. One had to be treated with emergency VP shunt before cranial expansion and the other with tapping of the ventricle at the same time with cranial expansion.

The skull X-ray showed typicalCLS with expanded middle cra- nial fossa, foreshortened anterior and posterior fossae and honey- comb appearance in the occiput. CLS often involves lambdoid and squamosal sutures 9 .

On the head CT scans of both patients, there were the synostosis involved almost all the cranial sutures including the lambdoid and squamosal sutures9. In both patients, due to the chronic and significantly increased ICP, complicated with hydrocephalus, the pressure upon the internal table of the skull became so great, meticulous and arduous dissection had to be carried out to avoid dural tear and bleeding. Excessive bleeding was also caused by the raised ICP. The mechanism of ventricular dilation in Crouzon syndrome is not clear, and there are various theories. It could be caused by constriction of the subarachnoid spaces, or it could be due to to obstruction of venous drainage from venouse sinuses, as suggested by Renier et al6.

Acanthosis nigricans is a skin condition characterized by thick, dark, velvety skin in body folds and creases, including the neck and underarms10.

\section{Conclusion}

Severely constricted head is an extreme manifestation and late stage of Crouzon syndrome. This could have been prevented by early diagnosis and multidisciplinary management according to established protocol.

\section{References}

1. Glaser RL, Jiang W, Boyadjiev SA, Tran AK, Zachary AA, Van Maldergem L, et al. Paternal origin of FGFR2 mutations in sporadic cases of Crouzon syndrome and Pfeiffer syndrome. Am J Hum Genet 2000;66:768-77.

2. Granger B., Evan G., John B., Analysis of Fronto-orbital Advancement for Apert, Crouzon, Pfeiffer, and Saethre-Chotzen Syndromes, 2000.

3. Renier D., Lajeunie E., Arnaud E., Marchac D., Management of craniosynostoses, 2000.

4. Ghassan S., Jeelani O., Dunaway D., Hayward R., Raised Intracranial pressure in crouzon syndrome : incidence, causer, and management., 2016.

5. Iannaccone G., Gerlini G., The So-called *Cloverleaf Skull Syndrome", 1974

6. Hanieh A., Sheen R., David J. David, Hydrocephalus in Crouzon's syndrome, 1989.

7. Granger B., Evan G., John B., Analysis of Fronto-orbital Advancment for Apert, Crouzon, Pfeiffer, and Saethre-Chotzen Syndromes, 2000.

8. David JD, Poswillo D, Simpson D. The Craniosynostoses: Causes, Natural History, and Management. Springer-Verlag London. 1982

9. Rohatgi M, Cloverleaf Skull - a Severe Form of Crouzon's Syndrome : a New Concept in Aetiology, 1991

10. Hill.J, Lister Hill National Center For Biomedical Communication, Crouzon Syndrome With Acanthosis Nigricans, 2018.

11. Guyuron R., Eriksson E., Persing J., Plastic Surgery Indcations and Practice, Saunders Elsevier, 2009

12. Irene, Guidline Treatment and Management of Craniosynostosis, The netherland Society for Plastic Surgery. 2010

13. Machado G, Di Rocco F, Sainte-Rose C, Meyer $P$, Marchac D, Macquet-Nouvion G, Arnaud E, Renier D (2011) Cloverleaf skull deformity and hydrocephalus. Childs Nerv Syst 27:1683-1691 